\title{
ASSESSING THE ICT TRAINING CONDITIONS FOR EDUCATIONAL MANAGERS
}

\author{
Javier Osorio \\ Las Palmas de Gran Canaria University. Department of Management. 35017 Las Palmas de \\ Gran Canaria. Spain
}

\begin{abstract}
Human resources are a critical issue of the Information Technology for Educational Management field (ITEM). Within this issue, computer usage training takes up a key position. In order to identify the potential and, therefore, the utility of a computerized information system the user will previously need to develop some skills to use it, which is possible with an adequate training process. However, experience shows that, very often, training programs are influenced by the environment of the training process. The purpose of this paper is to integrate previous research on training in order to develop a framework which can help identify opportunities and threats owing to environmental factors that can decisively affect a training program's success.
\end{abstract}

Key words: Training, educational management, environmental analysis, ICT

\section{INTRODUCTION}

Managers' effective use of information systems for educational management is a critical factor that can be an indicator of the information system's usefulness. Within this issue, training in computer usage plays a leading role due to the importance of knowing not only how to use the system but also its potential capacity. Therefore, the appropriate design of training courses is vitally important. Visscher and Branderhorst (2001) tried to establish a basis for the effective design of training courses in information systems usage for school managers. They started out with evidence of very little information and communication technology (ICT) support to

The original version of this chapter was revised: The copyright line was incorrect. This has been corrected. The Erratum to this chapter is available at DOI: 10.1007/978-0-387-35689-1_19 
managerial tasks, although most secondary schools ${ }^{6}$ in developed countries use computer-assisted school information systems to operate their organisations. According to these authors, this support is concentrated in the administrative area, thus ignoring the potential contribution to managerial work. There is no doubt that training school managers in computer usage is a very specific study field, so literature on this topic is scarce but exhaustive (see for instance Fung 1995; Selwood 1995 and Fulmer 1996). As stated by Visscher and Branderhorst (2001:148), although there is strong empirical evidence that user training greatly influences the degree of information systems usage, little is known about the ideal contents of courses to train educational managers in this matter. In their research project they tried to identify the characteristics that a training course should have in terms of contents and instructional features to successfully promote the managerial usage of computer supported school information systems.

However, a well-designed course can fail dramatically if other contextual factors are not taken into account. Most of those variables are external to the designer and cannot be controlled, although their negative impact can be foreseen and prevented and, on the other hand, their positive effects can be exploited. If the objective is to design a course that works, then it is also necessary to suit it to the constraints and the environment where it is going to take place. Analysis of environmental factors can offer a preview of the expected probability of success of the course's design and implementation. This success likelihood is directly related to the environment's attractiveness, and so a situation is attractive, that is to say, favourable for the training process, according to the results of analysis of external factors that can be of influence. Therefore, the probability of achieving training goals increases as attractiveness also does. The result of the analysis could be a sort of attractiveness measure associated with a recommended plan of action. Such a plan can lead either to progress in the course design and implementation or to stop and reconsider the situation, trying to discover alternative ways to change the environmental constraints in order to succeed.

The objective of this paper is to contribute to set an analysis framework to evaluate the likelihood of success in the development of training courses for utilization of computerized educational information systems at managerial level. With this aim in mind, the methodology to apply will consist on reviewing literature on contextual factors affecting the training process where variables such as ICT, management, organisational features and managers' profile are present. From the review, a list of factors will

${ }^{6}$ The same can be said about primary schools (Selwood et al. 1995; Nolan et al. 1998) and higher education institutions (Bricall, 2000). 
arise. Then a systematic method will be proposed to analyse the influence of such factors on the global attractiveness of the training process' environment. Finally, a measure indicating the most feasible plans of action will constitute the final output of the framework.

\section{ENVIRONMENTAL FACTORS}

There is a wide body of literature dealing with training issues. Having a look at journals focused on different areas of activity (i.e. business, healthcare, education, public sector) and even those focused on specific business functions (i.e. operations management, marketing, human resources) shows that training is a recurrent theme. They usually address precise matters and problems, setting important variables which are key for the success or failure of training programs carried out in the publications' scope. These variables are partly context-specific, but there is also a set of them that are present in almost all study areas, which can be catalogued as general variables. These general variables can be taken as a reference together with some other more specific ones adapted to the environment in which we centre our analysis.

We have identified several sets of variables extracted from different dimensions. All in all, they constitute the factors that may contribute to the success of a course on computer usage for educational managers. The purpose can be graphically described as shown in Figure 13-1. Here we can see that empirical evidence of high usefulness of educational managers' training in computer usage leads directly to consider which should be the contents of this training to ensure a profitable course, undoubtedly an important issue. However, between both dimensions there should also be some mechanism to evaluate contextual factors, those of an environmental nature, which can be decisive to guarantee that a training program can be designed and implemented with a high probability of success. 


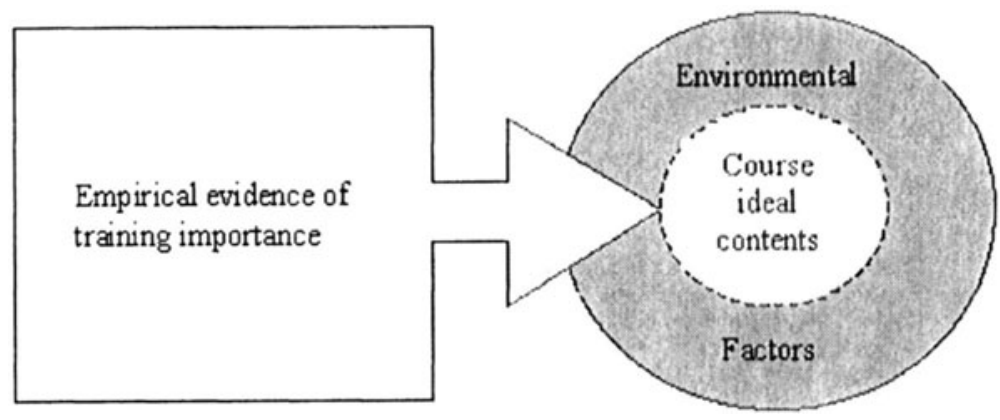

Figure 13-1. Elements of the training process

The analysis framework can be established referring to other authors' work on training topics. From a general perspective, most papers on the subject attempt to establish broad guidelines including general scope variables that experience has proven useful in almost every context. Many of these variables are applicable to any training process and they can be separated into two groups. The first one deals with personal motivation and the reasons that can encourage someone to engage in a training program. The second group relates to the availability of resources, that is to say, the means to aid achievement of training goals. Following previous research (Huczynski and Lewis 1980; Noe 1986; Baldwin and Ford 1988; Garavaglia 1993; Seyler et al. 1998; Gonzales et al. 1999), variables that can influence the training process have been included in the next two groups of factors:

Factor 1: Motivation (Perspectives after completing the training program).

- Expectancy of increased wages.

- Career development.

- Social reconnaissance.

- Personal self-esteem.

- Personal self-satisfaction.

- Increased capacity for autonomous decision-making. Factor 2: Availability of resources.

- Well-conditioned place.

- Material resources.

- Documentation.

- Easy access to trainer

- Course schedule.

Now we will proceed to identify three dimensions that comprise variables which have been mentioned in apparently disparate fields, but that can be usefully included in the topic dealt with in this paper. The reason lies in the varied nature of educational managers' training, where different matters converge. They are related to: 
1. Management work. Managers' specific training must concentrate on acquiring skills regarding unstructured problem analysis, access to sources of information, action planning, resource management and company activities supervision. However, managers' lack of time must not be forgotten, as it will limit their dedication to learning new skills.

2. Social and psychological attitudes related to computer usage. Factors such as prevalent organisational and individual values, the capacity to influence or be influenced by pressure groups, trainee's age and his/her previous training are of major importance. This is true in as much as the first sign of a training program's success or failure relates to trainees' attitude during the process.

3. New technologies training. Information technology, as any new technology, means new opportunities and threats to people who have to incorporate it into their professional activities. It can even block the introductory process unless factors such as job permanence, acceptance of innovation and leadership counteract, balancing the negative effect of aversion to change.

These three perspectives can be combined and reduced to two groups of variables (two factors). These can complement the two factors mentioned above (motivation and availability of resources) in order to make up the proposed framework for the environmental analysis of training conditions. The two latter groups could be established as follows:

Factor 3: Personal Profile.

- Age.

- Academic degree.

- Professional experience.

- Management experience.

- Familiarity with computers.

- Previous computer-related courses.

- Attitude towards new challenges.

- Time availability. Factor 4: Organisational Culture.

- Acceptance of innovation.

- Free flow of information within the organisation.

- Employees' involvement in redesigning organisational processes.

- Co-operation amongst employees.

- Capacity to take part in training designing.

- Level of knowledge management in the organisation.

- Institutional sponsorship of computer training.

Once these four factors have been identified, as well as the list of variables which in each case might influence the training program's success, it is time to articulate some sort of measure to use as reference in a particular 
training situation. The objective, as we have already mentioned, is to foresee to some extent the probability of the program's success. The concept of success in this context is a complex one. Nevertheless, we can agree that a training course on computer usage by educational managers may be tagged as 'successful' if, once concluded, the attendant has acquired the necessary skills to interact with the computer and has learnt to effectively apply these skills to improve his/her performance.

Therefore, the objective is to establish a global estimation of training conditions' attractiveness, which can favour or hinder a training process on computer usage for educational managers. This estimation can help identify actions to improve training results. If this estimation advises to proceed with the training process, then the next step would be to design the course contents, a matter that has been comprehensively addressed by Visscher and Branderhorst (2001).

\section{IMPLEMENTATION OF THE ANALYSIS FRAMEWORK}

Aiming to obtain an estimation of training's success, a sequence of steps is proposed. In general terms, the mechanism consists of making a succession of weighed averages in which weights will always be contingent on the situation in which the training program is going to take place. The first step would be to carry out a separate analysis of all the factors that influence the process.

Every factor will be analysed making use of the sets of related variables already identified. As not all variables have the same importance in the analysis context, they will be assessed on a scale that ranges from 0 to 10 . Justification of this method lies in the fact that some variables are more determinant than others for the courses' success. Thus, we try to avoid excessive simplifications that could erroneously concede all variables equal importance. It also tends to ensure prior examination of these variables by the course designer, who must take the organisation's features into account and decide which variables are truly important. Total values must add 10. This is just to make sure that results between the various factors involved in the analysis process are homogeneous.

Once variables have been pondered, the next step is to establish a value for the attractiveness profile of every variable within a specific factor. A Likert scale will be used, with values ranging from 1 (very low attractiveness) to 5 (very high attractiveness), with 3 as an intermediate and neutral value. This reflects the environment's situation regarding a certain 
variable and whether it contributes to make the training processes' environment more attractive.

The last step is just a mathematical one, which consists of multiplying weight by profile value for each variable, thus obtaining the weighed attractiveness profile. To this we add all weighed profiles previously calculated. The result of the addition will be an indicator of the degree of attractiveness for that factor. The total attractiveness value consequently ranges between 10 and 50. A value of 10 means that the factor under analysis contributes poorly, negatively indeed, to create a climate or environment which promotes a training program's success. At the opposite end, a value of 50 means a high or positive contribution to obtain an environment suited for a better training. Halfway, a value of 30 implies a neutral position, in which a factor does not affect the environment's attractiveness neither in a positive nor negative way. The next tables show examples of tables to obtain the attractiveness of each factor, starting with personal motivation. They are merely random examples that only intend to describe the analysis tool.

Table 13-1. Example of attractiveness calculation for the 'Personal motivation' factor

\begin{tabular}{|c|c|c|c|c|c|c|c|}
\hline \multicolumn{8}{|c|}{ PERSONAL MOTIVATION } \\
\hline \multirow{2}{*}{ Variables } & \multirow{2}{*}{ Weight } & \multicolumn{5}{|c|}{ Attractiveness Profile } & \multirow{2}{*}{$\begin{array}{c}\text { Weighed } \\
\text { Attractiveness } \\
\text { Profile }\end{array}$} \\
\hline & & \multicolumn{2}{|l|}{ V. Low } & \multirow{2}{*}{$\frac{\text { Neutral }}{3}$} & \multicolumn{2}{|r|}{ V. High } & \\
\hline & & 1 & 2 & & 4 & 5 & \\
\hline $\begin{array}{l}\text { Expectancy of } \\
\text { increased wages }\end{array}$ & 3.5 & & & $\sqrt{ }$ & & & 10.5 \\
\hline Career development & 2.5 & & & & & $\sqrt{ }$ & 12.5 \\
\hline Social reconnaissance & 1.5 & & $\sqrt{ }$ & & & & 3 \\
\hline Personal self-esteem & 1.0 & & & $\sqrt{ }$ & & & 3 \\
\hline $\begin{array}{l}\text { Capacity of } \\
\text { autonomous decision } \\
\text { making }\end{array}$ & 1.5 & & & $\sqrt{ }$ & & & 4.5 \\
\hline Total Weights: & 10 & & Tota & Attractive & ess: & & 33.5 \\
\hline
\end{tabular}

Comments to table 13-1: In this hypothetical case we see that 'Career development' is the best-profile variable (5), even though its weight (2.5) is lower than 'Expectancy of increased wages' (3.5) is. The latter variable's profile, though, is not so good (3). This shows that the prospect of a wage increase is ambiguous, in the sense that following the course does not guarantee an increase but neither does it rule it out completely. On the other hand, there are very good prospects for career development for those who take part in training. This is an important attractiveness and can ensure that course attendants become highly involved with it. 
Table 13-2. Example of attractiveness calculation for the 'Availability of resources' factor AVAILABILITY OF RESOURCES

\begin{tabular}{|c|c|c|c|c|c|}
\hline \multirow{2}{*}{ Variables } & \multirow{2}{*}{ Weight } & \multicolumn{3}{|c|}{ Attractiveness Profile } & \multirow{2}{*}{$\begin{array}{c}\text { Weighed } \\
\text { Attractiveness } \\
\text { Profile }\end{array}$} \\
\hline & & V. Low & \multirow{2}{*}{$\frac{\text { Neutral }}{3}$} & V. High & \\
\hline & & 12 & & 45 & \\
\hline Well-conditioned place & 3 & & & $\sqrt{ }$ & 12 \\
\hline Material resources & 2 & & & $\sqrt{ }$ & 8 \\
\hline Documentation & 1.5 & $\sqrt{ }$ & & & 3 \\
\hline Easy access to trainer & 1 & & $\sqrt{ }$ & & 3 \\
\hline Time availability & 2.5 & $\sqrt{ }$ & & & 5 \\
\hline Total Weights: & 10 & Tot & al Attracti & eness: & 31 \\
\hline
\end{tabular}

Comments to table 13-2: In this hypothetical case we can see that two highly important resources such as a well-conditioned space to carry out training (3) and availability of material resources (2) are conveniently offered by the organisation (attractiveness profile $=4$ ). This is a positive element in making the course more attractive. On the other hand, though, another outstanding variable such as the time availability because of the course's timetable (2.5) is not attractive (2), as it makes attendance difficult for trainees. As this could become a significant drawback some solution should be provided to overcome it, such as reducing working hours during the period covered by the course.

Table 13-3. Example of attractiveness calculation for the 'Personal profile' factor

\begin{tabular}{|c|c|c|c|c|c|c|c|}
\hline \multicolumn{8}{|l|}{ PERSONAL PROFILE } \\
\hline \multirow{2}{*}{ Variables } & \multirow{2}{*}{ Weight } & & & & & & \multirow{2}{*}{$\begin{array}{c}\text { Weighed } \\
\text { Attractiveness } \\
\text { Profile }\end{array}$} \\
\hline & & V. Low & & Neutral & & V. High & \\
\hline & & 1 & 2 & 3 & 4 & 5 & \\
\hline Age & 0.5 & & & $\sqrt{ }$ & & & 1.5 \\
\hline Academic degree & 1 & & & & $\sqrt{ }$ & & 4 \\
\hline $\begin{array}{l}\text { Professional } \\
\text { experience }\end{array}$ & 1 & & & & $\sqrt{ }$ & & 4 \\
\hline $\begin{array}{l}\text { Management } \\
\text { experience }\end{array}$ & 1 & & & $\sqrt{ }$ & & & 3 \\
\hline $\begin{array}{l}\text { Familiarity with } \\
\text { computers }\end{array}$ & 3 & & $\sqrt{ }$ & & & & 6 \\
\hline $\begin{array}{l}\text { Previous computer- } \\
\text { related courses }\end{array}$ & 2 & & $\sqrt{ }$ & & & & 4 \\
\hline $\begin{array}{l}\text { Attitude towards new } \\
\text { challenges }\end{array}$ & 1.5 & $\sqrt{ }$ & & & & & 1.5 \\
\hline Total Weights: & 10 & & Tota & Attractiv & ess: & & 24 \\
\hline
\end{tabular}

Comments to table 13-3: This hypothetical case reflects a common situation regarding computer usage training amongst executives of many 
organisations. Very often we find people with ample professional experience and high responsibilities within the company but with hardly any previous contact with computers. Highly weighed variables, such as familiarity with computers (3), previous computer-related courses (2) and the attitude towards new challenges (1.5) have a low attractiveness profile (values 2, 2 and 1 respectively). This results in a low total attractiveness rate for the 'Personal profile' factor (24). Therefore, course design must stress that training can be determinant to use computers as a regular work tool. It must also keep in mind attendants' low computer-related skills.

Table 13-4. Example of attractiveness calculation for the 'Organisational culture' factor ORGANISATIONAL CULTURE

\begin{tabular}{|c|c|c|c|c|c|c|}
\hline \multirow{3}{*}{ Variables } & \multirow{3}{*}{ Weight } & \multicolumn{4}{|c|}{ Attractiveness Profile } & \multirow{3}{*}{$\begin{array}{l}\text { Weighed } \\
\text { Attractiveness } \\
\text { Profile }\end{array}$} \\
\hline & & \multirow{2}{*}{ V. Low } & \multirow{3}{*}{$\frac{\text { Neutral }}{3}$} & & & \\
\hline & & & & \multicolumn{2}{|c|}{ V. High } & \\
\hline & & 12 & & 4 & 5 & \\
\hline Acceptance of innovation & 2 & & & & $\checkmark$ & 10 \\
\hline Free flow of information & 2.5 & & & $\sqrt{ }$ & & 10 \\
\hline $\begin{array}{l}\text { Employees' involvement in } \\
\text { redesigning organisational } \\
\text { processes }\end{array}$ & 1 & & & $\sqrt{ }$ & & 4 \\
\hline $\begin{array}{l}\text { Co-operation amongst } \\
\text { employees }\end{array}$ & 1 & & $\checkmark$ & & & 3 \\
\hline $\begin{array}{l}\text { Capacity to take part in the } \\
\text { training design }\end{array}$ & 2.5 & & & $\checkmark$ & & 10 \\
\hline $\begin{array}{l}\text { Degree of knowledge } \\
\text { management in the } \\
\text { organisation }\end{array}$ & 1 & & & $\checkmark$ & & 4 \\
\hline Total Weights: & 10 & Tote & 1 Attracti & eness: & & 41 \\
\hline
\end{tabular}

Comments to table 13-4: This hypothetical case shows a situation in which employees' concern in company affairs is highly valued, together with a strong tendency towards innovation and the acceptance of new management techniques. The high total attractiveness rate reached for 'Organisational culture' shows that the organisation makes developing training programs easy. The variable that considers the chance of attendants helping to design the course could be fundamental, as it implies a flexible attitude towards their needs, regarding, for example, the course's duration or it's schedule.

Once all four factors that influence a training programs environment have been analysed, the final step is to obtain an overall measure of attractiveness as a result of weighing all factors taken into account. Similarly to previous analysis, every factor has to be weighed using a scale from 0 to 10 according to their importance in the specific context in which the analysis takes place. This is because, once again, not all factors are equally important when 
designing a course. Each centre's situation and the context in which the program is to be developed imply the need to establish critical factors and how they will affect success likelihood according to their higher or lower attractiveness rate. The total weight must also be 10. Then, the previously calculated attractiveness values for every factor have to be multiplied by this weight to obtain a weighed value of attractiveness for every factor. The addition of these latter values constitutes the final global attractiveness rate. This value ranges from 100 to 500 . The higher the value the higher the attractiveness to design and implement a training program is as well and thus the probability of success. A value of 300 represents the middle point. This is an ambiguous situation where it is necessary to carefully analyse the opportunities and threats before going ahead with the training process. A result in the lower interval means that it is more advisable to try to improve the environmental situation or prevent threats than to proceed with the training program. The next table (5) shows an example of this last step of the analysis.

Table 13-5. . Example of global attractiveness calculation

\begin{tabular}{l|c|c|c}
\hline \multicolumn{1}{c|}{ Factors } & Weights & $\begin{array}{c}\text { Each factor's } \\
\text { attractiveness rate } \\
\text { (obtained from } \\
\text { previous tables) }\end{array}$ & $\begin{array}{c}\text { Weighed } \\
\text { factors' } \\
\text { attractiveness }\end{array}$ \\
\hline Personal motivation & 3 & 33.5 & 100.5 \\
Resources availability & 2 & 31 & 62 \\
Personal profile & 2 & 24 & 48 \\
Organisational culture & 3 & 41 & 123 \\
Total Weights: & 10 & Global & 333.5 \\
\hline
\end{tabular}

Comments to table13-5: This table contains results from previous factor's attractiveness analysis. Here the importance assigned to each factor is similar. The greatest threat for the course's success comes from the 'Personal profile' factor (attractiveness 24) and it should be given special attention when designing the course in order to avoid failure. On the other hand, the main chance of success comes from the 'Organisational culture' (attractiveness 41 ) which distinctly promotes training. 'Personal motivation' (attractiveness 33.5) and 'Availability of resources' (attractiveness 31) are neutral factors, as such values are close to the middle of the scale (30).

The global attractiveness value obtained can be placed on a graphic scale as shown in Figure 13-2, which reflects the success probability of the intended training program. Values to the right of 300 display an attractiveness that is favourable to developing the course. On the other hand, 
all values to the left of this middle point should be carefully evaluated before going ahead with training.

\section{FINAL THOUGHTS}

Obviously this framework has to be tested by means of a longitudinal analysis to demonstrate its usefulness. However, we consider that the idea that a training program's environment can decisively affect its outcome is intuitively valid. No matter how well a course's contents are designed, if the combination of external or environmental variables is not propitious the likelihood of success is severely diminished. This not only leads to considerable waste of effort and resources, but most importantly to psychological inhibition to further training. This is not an affordable cost in such a highly changing scenario as that of computerised educational management.

\begin{tabular}{|c|c|c|c|c|}
\hline \multirow[b]{2}{*}{$\begin{array}{l}\text { Very Low } \\
\text { Attract. }\end{array}$} & \multirow[b]{2}{*}{$\begin{array}{c}\text { Low } \\
\text { Attractiveness }\end{array}$} & \multicolumn{3}{|c|}{$\begin{array}{l}\text { Global attractiveness rate (represented by a circle) } \\
\text { resulting from previous hypothetical analysis. }\end{array}$} \\
\hline & & $\begin{array}{c}\text { Medium } \\
\text { Attractiveness }\end{array}$ & $\begin{array}{c}\text { High } \\
\text { Attractiveness }\end{array}$ & $\begin{array}{l}\text { Very High } \\
\text { Attract. }\end{array}$ \\
\hline 100 & 200 & 300 & 400 & 500 \\
\hline $\begin{array}{l}\text { It is probably } \\
\text { impossible to } \\
\text { carry out the } \\
\text { training program } \\
\text { due to lack of } \\
\text { resources or } \\
\text { severe problems } \\
\text { that prevent it. }\end{array}$ & $\begin{array}{l}\text { The training } \\
\text { program should } \\
\text { not be put into } \\
\text { practice due to a } \\
\text { high probability } \\
\text { of failure. }\end{array}$ & $\begin{array}{l}\text { Threats to the } \\
\text { program's } \\
\text { success should } \\
\text { be carefully } \\
\text { analysed in order } \\
\text { to find ways to } \\
\text { overcome } \\
\text { detected } \\
\text { problems. If } \\
\text { these cannot be } \\
\text { resolved, } \\
\text { postponing } \\
\text { training is } \\
\text { recommended. }\end{array}$ & $\begin{array}{l}\text { Even though } \\
\text { likelihood of } \\
\text { success is quite } \\
\text { high, it is } \\
\text { advisable to } \\
\text { examine } \\
\text { negative factors } \\
\text { and try to solve } \\
\text { them. }\end{array}$ & $\begin{array}{l}\text { The probability } \\
\text { of success is } \\
\text { high. The high } \\
\text { attractiveness } \\
\text { rate of all factors } \\
\text { can justify an } \\
\text { ambitious } \\
\text { training } \\
\text { program. }\end{array}$ \\
\hline
\end{tabular}

Figure 13-2. Graphic representation of the resulting global attractiveness value

\section{REFERENCES}

Baldwin, T. and Ford, J. (1988). Transfer of Training: A Review and Directions for Future Research. Personnel Psychology, 41, pp.63-106. 
Bricall, J. (2000). Informe Universidad 2000. Conferencia de Rectores de Universidades Españolas.

Cranton, P. (1994). Self Directed and Transformative Instructional Development. Journal of Higher Education, 65, 6, pp.727-744.

Fulmer, C. (1996). Training School Administrators to use Information Systems: A Review of Research. International Journal of Educational Research, 25, 4, pp.351-361.

Fung, A. (1995). "Managing Change in ITEM". In Information Technology in Educational Management, B. Barta, M. Telem and Y. Gev, (eds.), Chapman \& Hall, London.

Garavaglia, P. (1993). How to Ensure Transfer of Training. Training and Development Journal, 47, 10, pp.63-68.

Gonzales, B.; Ellis, Y.; Riffel, P. and Yager, D. (1999).. Training at IBMs Human Resource Service Center: Linking People, Technology and HR Processes. Human Resource Management, 38, 2, pp.135-142.

Huczynski, A. and Lewis, J. (1980). An Empirical Study into the Learning Transfer Process in Management Training. Journal of Management Studies, 17, pp.227-240.

Noe, R. (1986). Trainees Attributes and Attitudes: Neglected Influence on Training Effectiveness. Academy of Management Review, 11, pp.736-749.

Nolan, C.; Fulmer, C. and Taylor, R. (1998).. Four computerized school information systems: summary discussion. In The integration of information for educational management. (pp. 169-173), C. Fulmer, B. Barta and P. Nolan, (eds.), Felicity Press, Whitefield, ME.

Selwood, I. (1995). “The Development of ITEM in England and Wales". In Information Technology in Educational Management, B. Barta, M. Telem and Y. Gev, (eds.), Chapman \& Hall, London.

Selwood, I.; Wild, P. and Millin, D. (1995). Introduction of IT in school management: approaches, preparation, human and political aspects. Discussion held in the $1^{\text {st }}$ ITEM International Conference. In Information Technology in Educational Management, B. Barta, M. Telem and Y. Gev, (eds.), Chapman \& Hall, London.

Seyler, D.; Holton III, E.; Bates, R.; Burnett, M. and Carvalho, M. (1998). Factors Affecting Motivation to Transfer Training. International Journal of Training and Development, 2, 1, pp.2-16.

Visscher, A. and Branderhorst, E. (2001). How should School Managers be Trained for Managerial School Information System Usage? In Pathways to Institutional Improvement with Information Technology in Educational Management, P. Nolan, A. Fung and M. Brown, (eds.), Kluwer Academic Publishers. Boston. 